\title{
Article
}

\section{Antiviral Filtering Capacity of GO-Coated Textiles}

\author{
Federica Valentini ${ }^{1}\left(\mathbb{D}\right.$, Mara Cirone $^{2}{ }^{(0)}$, Michela Relucenti $\left.{ }^{3}{ }^{(}\right)$, Roberta Santarelli ${ }^{2}$, Aurelia Gaeta ${ }^{4}$, \\ Valentina Mussi ${ }^{5}$, Sara De Simone ${ }^{5}\left(\mathbb{D}\right.$, Alessandra Zicari ${ }^{2}$ and Stefania Mardente ${ }^{2, *(D)}$ \\ 1 Department of Sciences and Chemical Technologies, Tor Vergata University of Rome, \\ via della Ricerca Scientifica 1, 00133 Rome, Italy; federica.valentini@uniroma2.it \\ 2 Department of Experimental Medicine, Sapienza, University of Rome, Viale Regina Elena 324, \\ 00161 Rome, Italy; mara.cirone@uniroma1.it (M.C.); roberta.santarelli@uniroma1.it (R.S.); \\ alessandra.zicari@uniroma1.it (A.Z.) \\ 3 Department of Anatomical, Histological, Forensic and Orthopaedic Sciences, Sapienza University of Rome, \\ via Alfonso Borelli 50, 00161 Rome, Italy; michela.relucenti@uniroma1.it \\ 4 Department of Public Health and Infectious Diseases, Sapienza University of Rome, P. le A. Moro 5, \\ 00185 Rome, Italy; aurelia.gaeta@uniroma1.it \\ 5 Institute for Microelectronics and Microsystems, National Research Council, IMM-CNR, \\ Area della Ricerca Tor Vergata, via del Fosso del Cavaliere 100, 00133 Rome, Italy; \\ valentina.mussi@cnr.it (V.M.); sara.desimone@artov.imm.cnr.it (S.D.S.) \\ * Correspondence: stefania.mardente@uniroma1.it
}

Citation: Valentini, F.; Cirone, M.; Relucenti, M.; Santarelli, R.; Gaeta, A.; Mussi, V.; De Simone, S.; Zicari, A.; Mardente, S. Antiviral Filtering Capacity of GO-Coated Textiles. Appl. Sci. 2021, 11, 7501. https://doi.org/ 10.3390/app11167501

Academic Editor: Minas M. Stylianakis

Received: 14 June 2021

Accepted: 10 August 2021

Published: 16 August 2021

Publisher's Note: MDPI stays neutral with regard to jurisdictional claims in published maps and institutional affiliations.

Copyright: (c) 2021 by the authors. Licensee MDPI, Basel, Switzerland. This article is an open access article distributed under the terms and conditions of the Creative Commons Attribution (CC BY) license (https:/ / creativecommons.org/licenses/by/ $4.0 /)$.
Abstract: Background. New antiviral textiles for the protection and prevention of life-threatening viral diseases are needed. Graphene oxide derivatives are versatile substances that can be combined with fabrics by different green electrochemistry methods. Methods In this study, graphene oxide (GO) nanosheets were combined with textile samples to study GO antiviral potential. GO synthesized in the Chemistry laboratories at the University of Rome Tor Vergata (Italy) and characterized with TEM/EDX, XRD, TGA, Raman spectroscopy, and FTIR, was applied at three different concentrations to linen textiles with the hot-dip and dry method to obtain filters. The GO-treated textiles were tested to prevent infection of a human glioblastoma cell line (U373) with human herpesvirus 6A (HHV-6A). Green electrochemical exfoliation of graphite into the oxidized graphene nanosheets provides a final GO-based product suitable for a virus interaction, mainly depending on the double layer of nanosheets, their corresponding nanometric sizes, and Z-potential value. Results Since GO-treated filters were able to prevent infection of cells in a dose-dependent fashion, our results suggest that GO may exert antiviral properties that can be exploited for medical devices and general use fabrics.

Keywords: graphene oxide; double layers; functionalized nanosheets; antiviral features; linen textiles; HHV-6

\section{Introduction}

Pathogenic microorganisms, such as viruses in the environment, use different routes to bring about infection and cause disease that may seriously compromise public health; the SARS-CoV2 virus, for example, can be easily transmitted through droplets or aerosol and can be inhaled or deposited on the surface of objects with which people may come into contact. New solutions are therefore needed to protect people from inhaling viral agents or to disinfect surfaces better.

Nanomaterials are useful in the fight against viral infection. Carbon-based nanomaterials in particular, by virtue of their low cytotoxicity, high biocompatibility, and wide spectrum of applications, are important as virucidal substances and for preventing infection. Graphene derivatives have been shown to have antibacterial activity in a number of ways [1]; for example, the authors have recently demonstrated that GO disrupted the bacterial wall and induced oxidative stress in a dose-dependent mode [2].

Although researchers are interested in knowing the antiviral properties of GO, there are still few studies that report its direct antiviral effects. Some reports demonstrate that 
GO's negative charges may disrupt viral envelope proteins [3]. According to these authors, the physical interaction of the viruses with GO's sharp edges is at the origin of the antiviral activity [4].

The impact of the charge on GO anti-viral function seems to be related to the link with ionic and/or nonionic polymers [5]. In particular, the interaction of GO functionalized with ionic polyglycerol sulfate and/or fatty amine functionalities platform with Herpes Simplex Virus type 1 (HSV-1) has been widely studied, where the HSV-1 is a virus model system similar to the one used in this study. The combination of sulfate and alkyl chains produces binding of the virus through electrostatic interaction with the polyglycerol sulfate (ionic polymer), while the alkyls (the non-ionic counterpart of polymers) induce a high level of antiviral activity through secondary hydrophobic interaction. Longer alkyl chains exhibited the highest level of antiviral activity, but they are also toxic against Vero cells [6] For GO functionalization aimed at virus inhibition, it is, therefore, best to use polymers with $\mathrm{C} 6$ and $\mathrm{C} 9$ as hydrocarburic alkyl chains.

Nanoparticle size and shape both have a significant impact on inhibitory efficiency. Regarding size, a higher inhibitory effect has mainly been observed in the presence of the small GO sheets, when compared to medium and large GO nanosheets [7]. This effect can be explained considering both aspects, as the bending and the cooperative encapsulation.

Regarding shape, some authors report [8] that virus destruction and deactivation mainly occur only in the presence of negatively charged sharp-edged GO nanosheets. Ye et al. [8] report about the antiviral activity of GO against two different viruses, showing that low non-cytotoxic concentrations of GO suppress infection of target cells by deactivating the virus particles prior to entry into the cell. The same authors also analyzed GO structure and concluded that nanosheets were able to inactivate both viruses by structural destruction before entry into cells.

The shape parameter of nanomaterials is also taken into consideration in other studies because different antiviral effects have been observed when the nanomaterial shape changes from nanosheets to spherical nanoparticles. As shown with gold nanoparticles, different phases of viral infection can be inhibited by nanoparticles [9].

The application of gold nanoparticles derivatized with mercaptoethanesulfonate ( $\mathrm{Au}-$ MES NPs) as effective inhibitors of Herpes simplex virus type 1 infection based on their ability to mimic cell-surface-receptor heparan sulfate has been fully described. Several characterization studies have shown that Au-MES NPs interfere with viral bonding/interaction, entry, and cell-to-cell spread, preventing subsequent viral infection in different ways. A recent technique being used to reduce or prevent viral infection is to coat cell surfaces with functionalized GO, metal-based nanoparticles [10], and nanocomposites. Nanomaterials thus contribute to highly effective, antiviral technologies that are suitable for producing smart textiles, devices, and tools that can act and react against lethal viruses and new invasive forms of bacteria [11,12].

In this study, a chemically synthesized GO sample was applied as a coating to linenbased textiles (GO/TxT) to investigate whether it could acquire antiviral properties; the human herpesvirus 6 (HHV-6A) was used as a model.

\section{Materials and Methods}

\subsection{Materials and Reagents}

Extra pure graphite fine powder (the precursor of graphene oxide), $\mathrm{H}_{2} \mathrm{SO}_{4}, \mathrm{HNO}_{3}$, and ethanol were purchased by Sigma Aldrich (Merck, Darmstadt, Germany). All reagents are of analytical grade and used as received. A Milli-Q pore apparatus system was applied to produce distilled water for all aqueous solutions.

Linen textiles were purchased by a fabric company and used as received.

\subsection{Graphene Oxide (GO) Synthesis}

GO was synthesized using the method outlined in our previous study [13]. $200 \mathrm{mg}$ of Graphite fine powder were dispersed in $200 \mathrm{~mL} \mathrm{HNO}_{3} / \mathrm{H}_{2} \mathrm{SO}_{4}(1: 3 v / v)$ and sonicated for 
$8 \mathrm{~h}$ with a polytronic probe, tip diameter $13 \mathrm{~mm}$, at $50 \mathrm{~W}$ and $45^{\circ} \mathrm{C}$ (Sonifier 450 Advances; Branson, Danbury, CT, USA). Samples were then washed with distilled water, centrifuged at $13,000 \mathrm{rpm}$ for $15 \mathrm{~min}$, and oven-dried at $100{ }^{\circ} \mathrm{C}$.

\subsection{GO Modified Textiles}

Linen textiles were provided by an Italian textile industry that has asked to remain anonymous until the completion of the patent procedures. GO coating of textiles was performed by hot dipping and then drying in a controlled atmosphere (under patent).

Final aqueous GO dispersion $(1 \mathrm{mg} / \mathrm{mL})$ was ultra-sonicated for $1 \mathrm{~h}$ at $50 \mathrm{~mW}$ and R. T.

$\left(25^{\circ} \mathrm{C}\right)$ and resuspended at $0.5 \%, 1 \%$ and $10 \%(w / v)$ before being applied to linen textiles.

The resulting GO-modified textiles were labeled as: $(\mathrm{GO}-\mathrm{T})_{0.5} ;(\mathrm{GO}-\mathrm{T})_{1} ;(\mathrm{GO}-\mathrm{T})_{5} ;(\mathrm{GO}-\mathrm{T})_{10}$.

\subsection{GO Characterization}

Several characterization techniques were applied for morphological, structural, and microanalysis study of GO (compared with graphite precursor).

\subsubsection{Transmission Electron Microscopy (TEM)/EDX}

For TEM analysis, GO was dispersed in ethylic alcohol, deposited on a copper grid $(\mathrm{Cu}, \varphi=3 \mathrm{~mm}$ ), air-dried, and observed with Philips EM208S TEM (FEI, Thermo Fisher, Waltham, MA, USA), equipped with an Olympus MegaView SIS camera.

\subsubsection{Atomic Force Microscopy (AFM) Study}

AFM experiments were carried out in the air using a Veeco Multiprobe IIIa instrument. Experiments were performed in tapping mode by using Si tips with a spring constant of $\sim 40 \mathrm{~N} / \mathrm{m}$ and a typical curvature radius on the tip of $7 \mathrm{~nm}$. The graphene oxide sample was dispersed in distilled water to a final concentration of $0.01 \mathrm{mg} \mathrm{mL}^{-1}$ and then deposited on Mica substrates.

\subsubsection{X-ray Diffraction Analysis (XRD)}

$X$-ray diffraction [14], using $\mathrm{CuK} \alpha$ radiation at $40 \mathrm{keV}$ in a $\theta-2 \theta$ diffractometer ( $\mathrm{X}^{\prime}$ Pert PRO Phillips), was used to determine the presence and structure of calcium carbonate particles and their crystallinity.

\subsubsection{X-ray Photoelectron Spectroscopy (XPS)}

XPS was applied using an Omicron DAR $400 \mathrm{Al} / \mathrm{Mg}$ Ka non-monochromatized X-ray source, and a VG-CLAM2 electron spectrometer. GO was dispersed in ethanol, as a working medium, to reach a final concentration of $1 \mathrm{mg} \mathrm{mL}^{-1}$ and homogeneously deposited on silicon wafer support.

\subsubsection{Thermo Gravimetric Analysis (TGA)}

TGA analysis was carried out on solid graphite (as a precursor), and GO samples in a TGA instrument to $900{ }^{\circ} \mathrm{C}$, at a heating rate of $5^{\circ} \mathrm{C} \min ^{-1}$ under $\mathrm{N}_{2}$ atmosphere.

\subsubsection{Raman Spectroscopy}

Raman measurements were carried out with a DXR2xi Thermo Scientific Raman Imaging spectrometer, both on Graphite and GO samples prepared as solid powders placed on a glass slide and the GO-coated textiles. The instrument was equipped with an Electron-multiplying CCD (EMCCD) as a detector and a solid-state laser (with an emission wavelength, $\lambda_{\text {emission }}=532 \mathrm{~nm}$ ) as a light source. The excitation power was $5 \mathrm{~mW}$ and the laser was focused on the sample with a $50 \times$ long focal distance objective. The signal was collected using the same objective in a backscattering configuration and each spectrum was the result of 300 accumulations of $0.1 \mathrm{~s}$ acquisitions. The spectral resolution was $2 \mathrm{~cm}^{-1}$ (full range grating with 900 lines $/ \mathrm{mm}$ ). 


\subsubsection{Fourier Transform Infrared Spectroscopy (FTIR)}

FTIR spectroscopy was carried out in transmittance mode on samples embedded in KBr pellets, using an FT-IR spectrophotometer, (Shimadzu Model Prestige 21).

\subsubsection{Z-Potential}

$\mathrm{Z}$ potential $(\xi / \mathrm{mV})$ measurements were carried out with a Zetasizer Nano ZS equipment (Malvern, UK), equipped with a back-scattering detection mode (with an angle of $173^{\circ}$ ), and a laser He-Ne at $633 \mathrm{~nm}$ wavelength (Laser Doppler Velocimetry).

\subsubsection{GO Modified Textiles Characterization}

The $(\mathrm{GO}-\mathrm{T})_{0.5} ;(\mathrm{GO}-\mathrm{T})_{1} ;(\mathrm{GO}-\mathrm{T})_{5}$ and $(\mathrm{GO}-\mathrm{T})_{10}$ samples were characterized by Raman, FTIR, and SEM/EDX (Scanning Electron Microscopy/Energy Dispersive X-ray Analysis) techniques. A textile sample without GO coating was used as a control (CTRL).

\subsubsection{VP-SEM Engineered Textiles Characterization Protocol}

$1 \mathrm{~cm}^{2}$ of two textile samples (with and without GO coating) were observed by Hitachi SU3500 VP-SEM, under operating conditions of $5 \mathrm{kV}$ and $60 \mathrm{~Pa}$. Observations were carried out under conditions of variable pressure; since this technique is elective for morphological analysis of delicate structures, no tissue preparation is needed and images reflect actual sample structure, without artifacts due to reagents.

\subsubsection{SEM Characterization Engineered Textiles}

To identify viral particles adhering to tissues, $1 \mathrm{~cm}^{2}$ of three textile samples (GO ratio: $1 \%, 5 \%, 10 \%$ ) were prepared as follows: samples were fixed in glutaraldehyde $2.5 \%$ in PBS $0.1 \mathrm{M} \mathrm{pH} 7.4$ for at least $48 \mathrm{~h}$ at $4{ }^{\circ} \mathrm{C}$; they were then rinsed in PBS and postfixed with a mixture of $\mathrm{OsO}_{4} 2 \%$ and Ruthenium Red $0.2 \% v / v$ for $2 \mathrm{~h}$; they were then gently rinsed in $\mathrm{dH}_{2} \mathrm{O}$ to discard post-staining reagents and dried on absorbent paper sheets; samples were then mounted on an aluminum stub with adhesive carbon tape and observed by Hitachi SU3500 at operating conditions of $10-12 \mathrm{kV}$ and high vacuum.

\subsubsection{Cell Culture, Reagents and Infection}

U373-MG, a human glioblastoma astrocytoma cell line, was cultured in RPMI-1640 medium, containing L-glutamine $(2 \mathrm{mM})$, streptomycin $(100 \mu \mathrm{g} / \mathrm{mL})$ (Corning, NY, USA; 30-002), penicillin (100 U/mL) (Corning Incorporated, Corning, NY, USA; 25-005) and supplemented with $10 \%$ Fetal Bovine Serum (FBS) (Corning, NY, USA; $35-079$ ), at $37^{\circ} \mathrm{C}$ in a $5 \% \mathrm{CO}_{2}$ incubator.

HHV-6A was prepared as previously described [15]. 15.000/well U373-MG cells were then seeded in $500 \mu \mathrm{L}$ of RPMI-1640 medium in 24 wells/plate and cultured for 24 h. $(\mathrm{GO}-\mathrm{T})_{0.5} ;(\mathrm{GO}-\mathrm{T})_{5} ;(\mathrm{GO}-\mathrm{T})_{10}$ filters were then cut and placed on modified Boyden chambers (Thermo Scientific, Denmark) with a $0.8 \mu \mathrm{m}$ porous filter between the upper and lower wells. $150 \mu \mathrm{l}$ of RMPI containing 350.000 viral genome copy number were dispensed on the top well with graphene oxide-coated textile $/ 0.8 \mu \mathrm{m}$ filter and also into the uncoated textile $/ 0.8 \mu \mathrm{m}$ filter (CTRL $0.8 \mu \mathrm{m}$ ) and the $0.8 \mu \mathrm{m}$ porous filter without textile. The latter was used as a positive control of infection, as HHV-6 can easily cross $0.8 \mu \mathrm{m}$ filters, while viruses do not normally pass through $0.2 \mu \mathrm{m} /$ diameter filters (CTRL $0.2 \mu \mathrm{m}$ ). Conversely, mock-infected U373-MG cells were used as negative control (CTRL no filter). Plates were incubated for $72 \mathrm{~h}$ at $37^{\circ} \mathrm{C}$; cells were then counted and viability was determined with Trypan blue exclusion test. Lysates were subjected to real-time PCR (qPCR) to evaluate the HHV-6 genome copy number. DNA extraction was carried on from plasma samples using the Nuclisens EasyMag instrument (BioMerieux S.p.A.) according to the manufacturer's instructions. Extracted samples were then analyzed for the presence of HHV6- DNA by quantitative TaqMan real-time Polymerase Chain Reaction (PCR), using a commercially available kit that amplifies a sequence relative to ORF 13R region, U67 gene 
(ELITechGroup S.p.A.) using ABI 7300 real-time PCR System (Applied Biosystem). After infection experiments, filters were removed and harvested for SEM.

\section{Results}

\subsection{Characterization of GO Nano Sheets}

GO nanosheet characterization is shown in Table 1 and Figures 1 and 2.

Table 1. Characterization of functionalized graphene oxide, GO.

\begin{tabular}{|c|c|c|c|c|c|}
\hline Samples & $\begin{array}{c}\text { AFM } \\
\text { Thickness (nm) } \\
\left(\mathbf{N}^{\circ} \text { Layers }\right)\end{array}$ & $\begin{array}{l}\text { AFM } \\
\text { Area } \\
\left(\mu \mathrm{m}^{2}\right)\end{array}$ & $\begin{array}{c}\text { XPS_C1s } \\
\text { Oxygen Groups } \\
\text { (At. \%) } \\
\text { Peak BE (eV) }\end{array}$ & $\begin{array}{c}\text { FTIR } \\
\text { Assigned Bands } \\
\left(\tilde{v}, \mathrm{~cm}^{-1}\right)\end{array}$ & $\begin{array}{c}\text { SEM/EDX } \\
\text { Microanalysis }\end{array}$ \\
\hline GO & $\begin{array}{c}1.4 \pm 0.6 \\
(2-3)\end{array}$ & $5 \times 10^{-2}-0.2$ & $\begin{array}{c}\text { C-O } \\
(21.71 \text { At. \%) } \\
286.6(\mathrm{eV}) \\
\mathrm{C}=\mathrm{O} \\
(18.32 \mathrm{At.} \%) \\
287.7(\mathrm{eV})\end{array}$ & $\begin{array}{c}\mathrm{OH} \\
\text { (Strong bands) } \\
\tilde{v}=3413 \\
\mathrm{C}(=\mathrm{O}) \\
\text { (Medium bands) } \\
\tilde{v}=1722 \\
\mathrm{CO} \\
\text { (Weak bands) } \\
\tilde{v}=1076\end{array}$ & $\begin{array}{c}\mathrm{Si}, \mathrm{S}, \mathrm{Ca}, \mathrm{Cr}, \\
\mathrm{Fe}, \mathrm{Co}, \mathrm{Ni}, \mathrm{Y} \\
\text { are absent and } \\
\text { not detectable }\end{array}$ \\
\hline
\end{tabular}

A

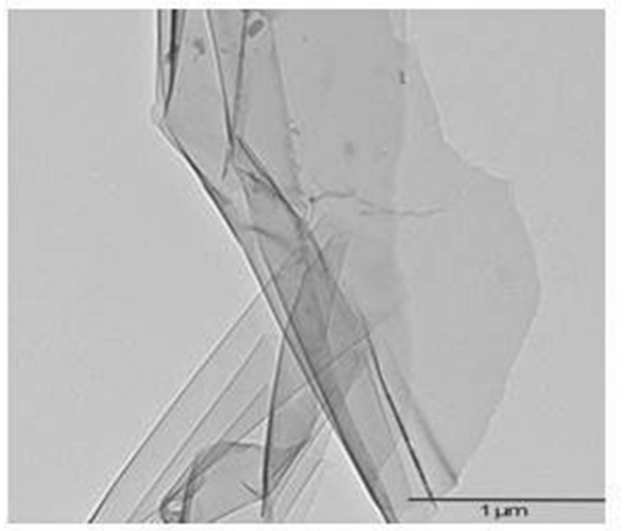

C

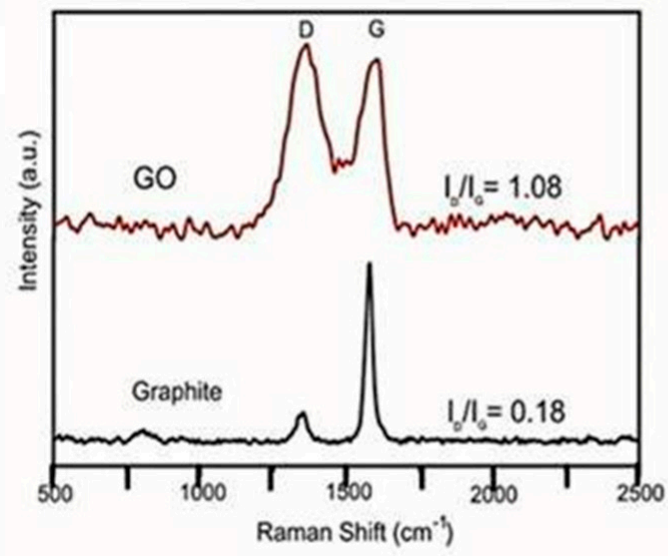

B

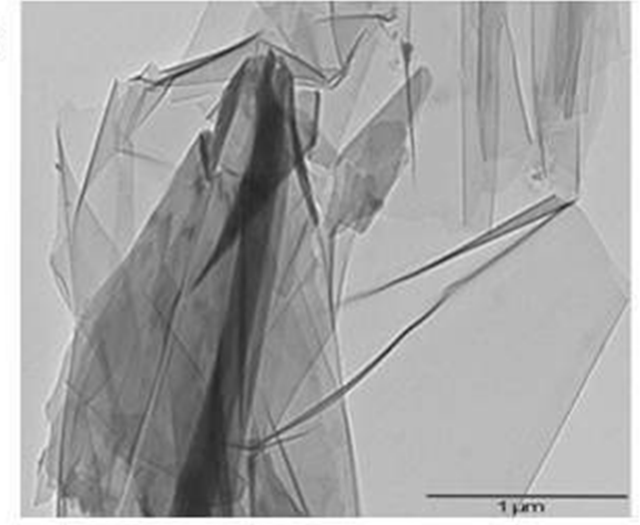

D

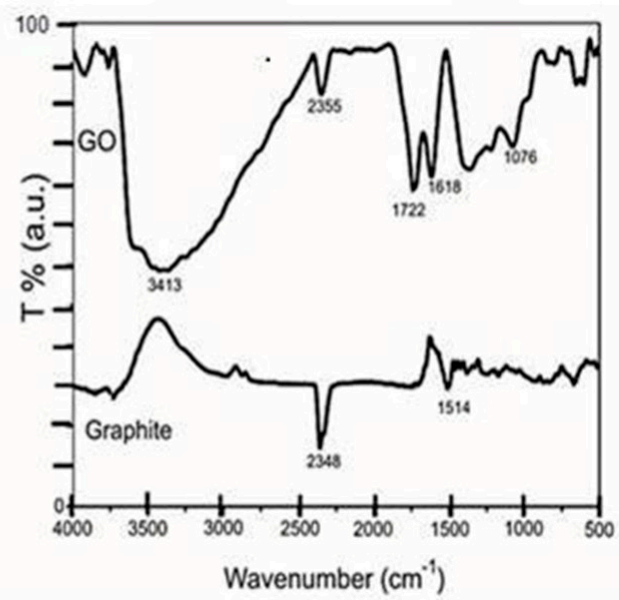

Figure 1. GO characterization: (A,B) TE_micrographs of GO; (C) Raman spectrum for both carbon-based materials; and (D) FTIR spectrum profile for GO and graphite samples, respectively. 

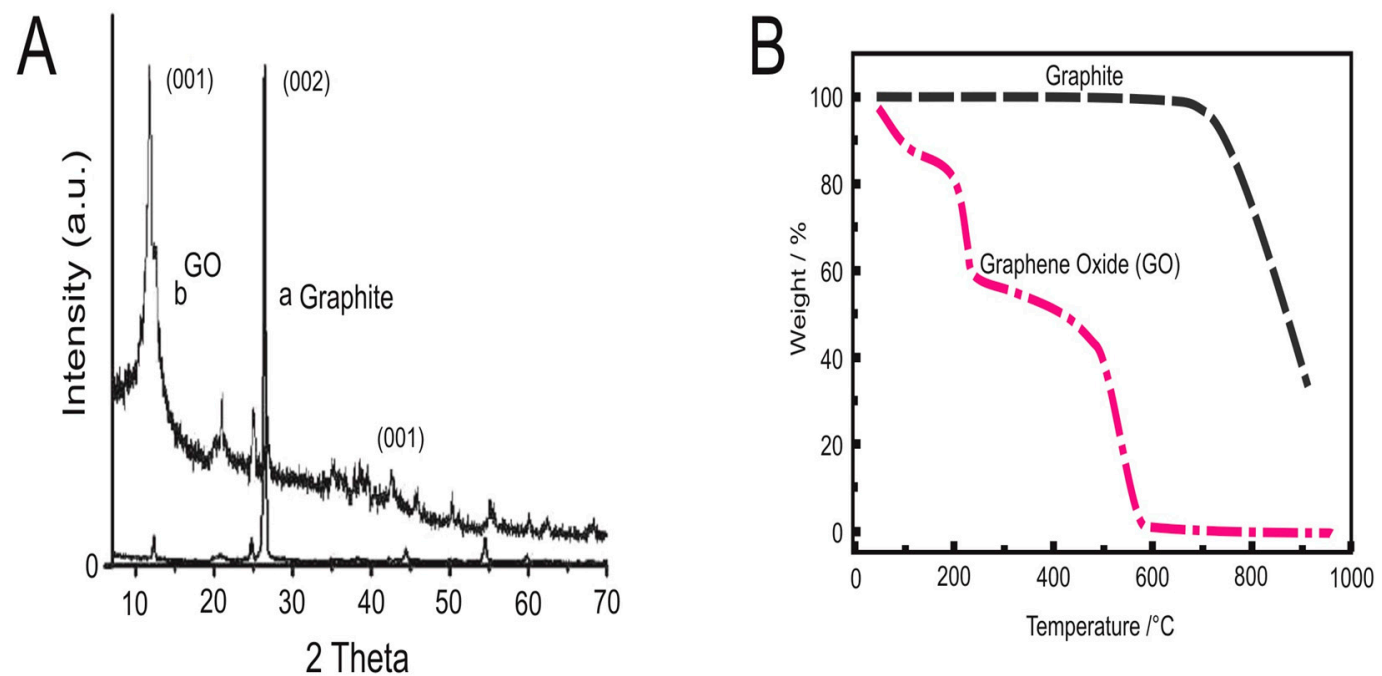

Figure 2. (A): XRD profiles of Graphite (a) and GO (b); (B): TGA curves for GO (pink curve line) and graphite (black curve line).

Figure 1A,B show the morphology of GO nanosheets, while their area and thickness have been quantified by AFM, reported in Table 1 .

The functionalization of GO was highlighted by the Raman study, shown in Figure 1C, where the presence of a more intense $\mathrm{D}$ band compared to the one exhibited by the graphite sample and the highest $\mathrm{I}_{\mathrm{D}} / \mathrm{I}_{\mathrm{G}}$ ratio confirmed the presence of oxygenated functionalities on the GO surface, edge and sides. The FTIR study (Figure 1D) shows the different functional groups in graphite and GO samples. The peak centered at $3413 \mathrm{~cm}^{-1}$ is mainly due to the $\mathrm{O}-\mathrm{H}$ stretching modes that combined with the signal recorded at $1722 \mathrm{~cm}^{-1}$ (mainly related to the $\mathrm{C}(=\mathrm{O})$ stretching modes) reveals the functionalization of $\mathrm{GO}$, mainly by the anchored carboxylic groups (,i.e., $\mathrm{C}(=\mathrm{O})-\mathrm{OH})$. Absorption bands around $2355 \mathrm{~cm}^{-1}$ represented the symmetric and asymmetric $\mathrm{C}-\mathrm{H}$ stretching modes, while the signals recorded at 1618 and $1076 \mathrm{~cm}^{-1}$ are representative of $\mathrm{C}=\mathrm{C}$ groups from unoxidized sp ${ }^{2} \mathrm{C}=\mathrm{C}$ bonds of graphite stretching vibration modes and $\mathrm{C}-\mathrm{O}$ vibrations of GO sample respectively [16,17]. The FTIR investigation highlights the formation of GO and its hygroscopic features due to the presence of oxygenated functional groups. The FTIR results were confirmed by XPS characterization reported in Table 1 and published in our previous paper [18].

The oxygenated functional groups on GO samples have been also investigated by Z-potential measurements, reported in Table 2. As shown in Table 2, the GO appears as a negatively charged material (due to carboxylates groups, $\mathrm{C}=(\mathrm{O})-\mathrm{OH})$, while viral capside alone was positively charged. Conjugation of GO and HHV-6A resulted in a more positively charged GO/HHV-6A new composite material.

Table 2. Z-potential of the functionalized GO, the human herpesvirus 6A (HHV-6A), and the subsequent conjugation with the GO.

\begin{tabular}{cc}
\hline Samples & $\begin{array}{c}\text { Z-Potential } \\
\text { 乙 } \mathbf{( m V )}\end{array}$ \\
\hline GO & $-40.5 \pm 0.2$ \\
human herpesvirus 6A (HHV-6A) & $+18.7 \pm 0.5$ \\
GO/6A (HHV-6A) conjugation & $+16.9 \pm 1.0$ \\
\hline
\end{tabular}

The XRD spectrum (Figure 2A) shows both profiles for GO and Graphite. The dry $\mathrm{GO}$ and Graphite powders were directly used in the X-ray diffraction (XRD) analysis. The XRD measurement shows that the (002) diffraction peak of Graphite (Figure 2A appears at ca. $26.6^{\circ}$, and the interlay space is ca. $0.34 \mathrm{~nm}$. After oxidation, the interlay space of GO 
$\left(11.8^{\circ}, 0.75 \mathrm{~nm}\right.$, Figure 2B is larger than that of the pure graphite as a consequence of the introduction of oxygenated functional groups on carbon sheets.

TGA performed on natural graphite and GO heated to $900^{\circ} \mathrm{C}$ at a heating rate of $5{ }^{\circ} \mathrm{C}$ min $^{-1}$ under $\mathrm{N}_{2}$, evidenced that GO is thermally unstable and starts to lose mass when heated even below $100{ }^{\circ} \mathrm{C}$, and there are two significant drops in mass at around $226^{\circ} \mathrm{C}$ and $541{ }^{\circ} \mathrm{C}$, respectively. The above drops in mass are due to the decomposition of the labile oxygen-containing functional groups, yielding $\mathrm{CO}, \mathrm{CO}_{2}$, and steam. The final part of the TGA curve, starting from $600{ }^{\circ} \mathrm{C}$ up to $1000{ }^{\circ} \mathrm{C}$, is related to the pyrolysis of the GO carbon $\left(\mathrm{C} \mathrm{sp}^{2}\right)$ skeleton. The natural graphite shows a typical TGA profile, where at $800{ }^{\circ} \mathrm{C}$, the carbon-based materials pyrolysis event, significantly occurs. Regarding the natural graphite TGA profile, the only significant mass loss appears at around $800{ }^{\circ} \mathrm{C}$, related to pyrolysis.

\subsection{Characterization of Textiles with and without Coating}

Figure 3 shows SEM of the textiles before and after the coating process with $10 \%$ GO. The general architecture of textile is maintained after coating with GO. The coating process which upholsters the fibers and smooths their surface extends from one fiber to another in the form of a thin lamina.

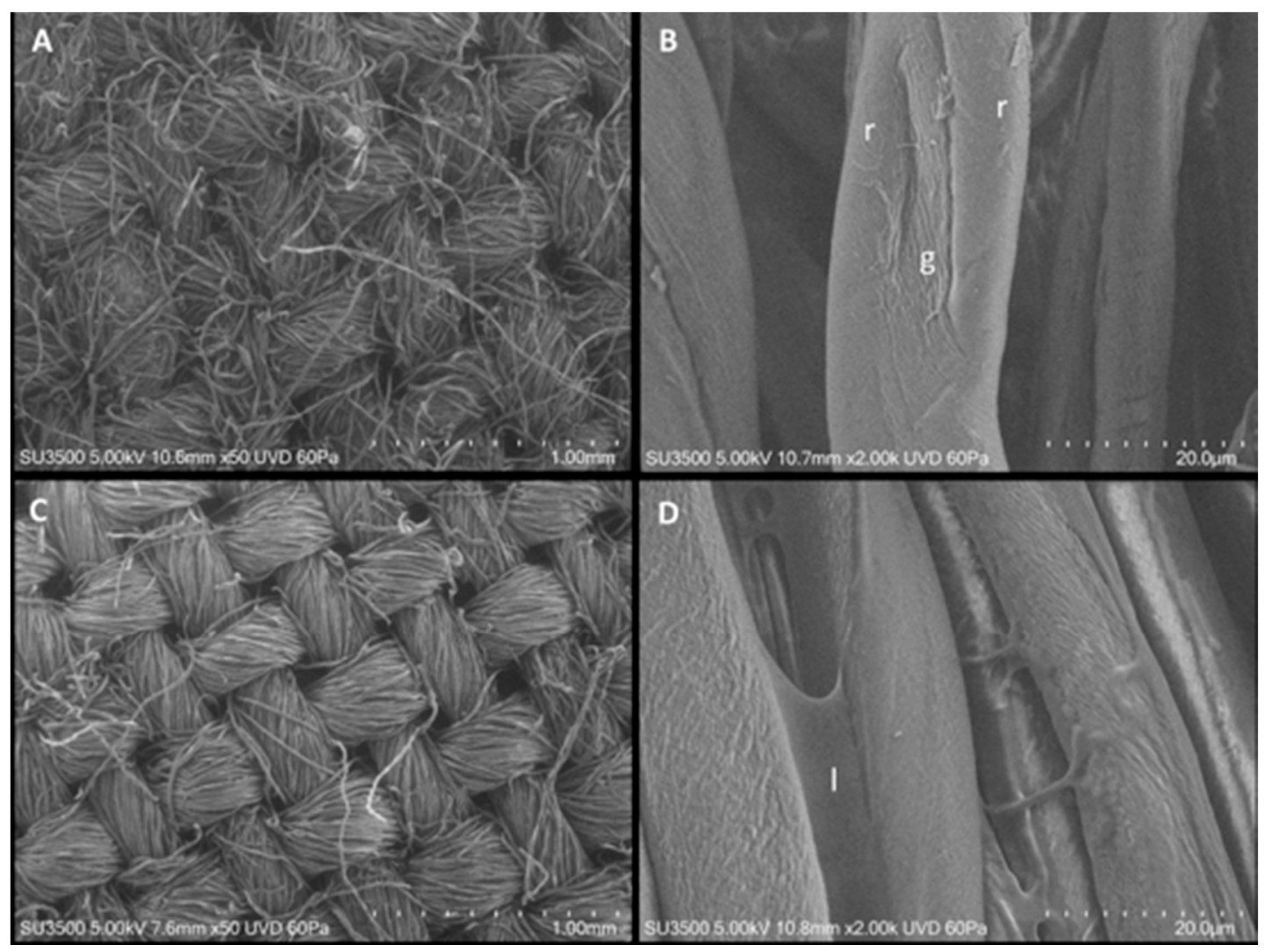

Figure 3. VP-SEM characterization of textiles without coating $(\mathbf{A}, \mathbf{B})$ and with coating $(\mathbf{C}, \mathbf{D})$. Textile without coating is imaged at $50 \times$, scale bar $1 \mathrm{~mm}$ (A). The texture of the weaving is visible. It is formed by bundles of fibers arranged in a messy way (B). Textile single fiber is imaged at $2000 \times$, scale bar $20 \mu \mathrm{m}$, it appears similar to a ribbon, longitudinally grooved by a gutter $(\mathrm{g})$, which is limited at the sides by bulging ridges (r). Fiber surface appears wrinkled in some parts, exfoliated in others. (C) GO-coated textile is imaged at $50 \times$, scale bar $1 \mathrm{~mm}$. The texture of the weaving is visible, fiber bundles appear as having a more compact and ordered aspect. (D) Coated textile fibers are imaged at $2000 \times$, scale bar $20 \mu \mathrm{m}$. (1).

Raman analysis was carried out on GO-coated fibers. Several spectra were acquired directly on GO clusters identified on the three samples treated with different concentrations of GO $(1 \%, 5 \%$, and $10 \%)$. Spectra collected for similar clusters found on the three samples 
are shown, respectively, in Figure 4A (GO 1\%, blue curve), Figure 4B (GO 5\%, black curve) and Figure $4 \mathrm{C}$ (GO 10\%, red curve), together with the background signal corresponding to the linen fibers (green curve).
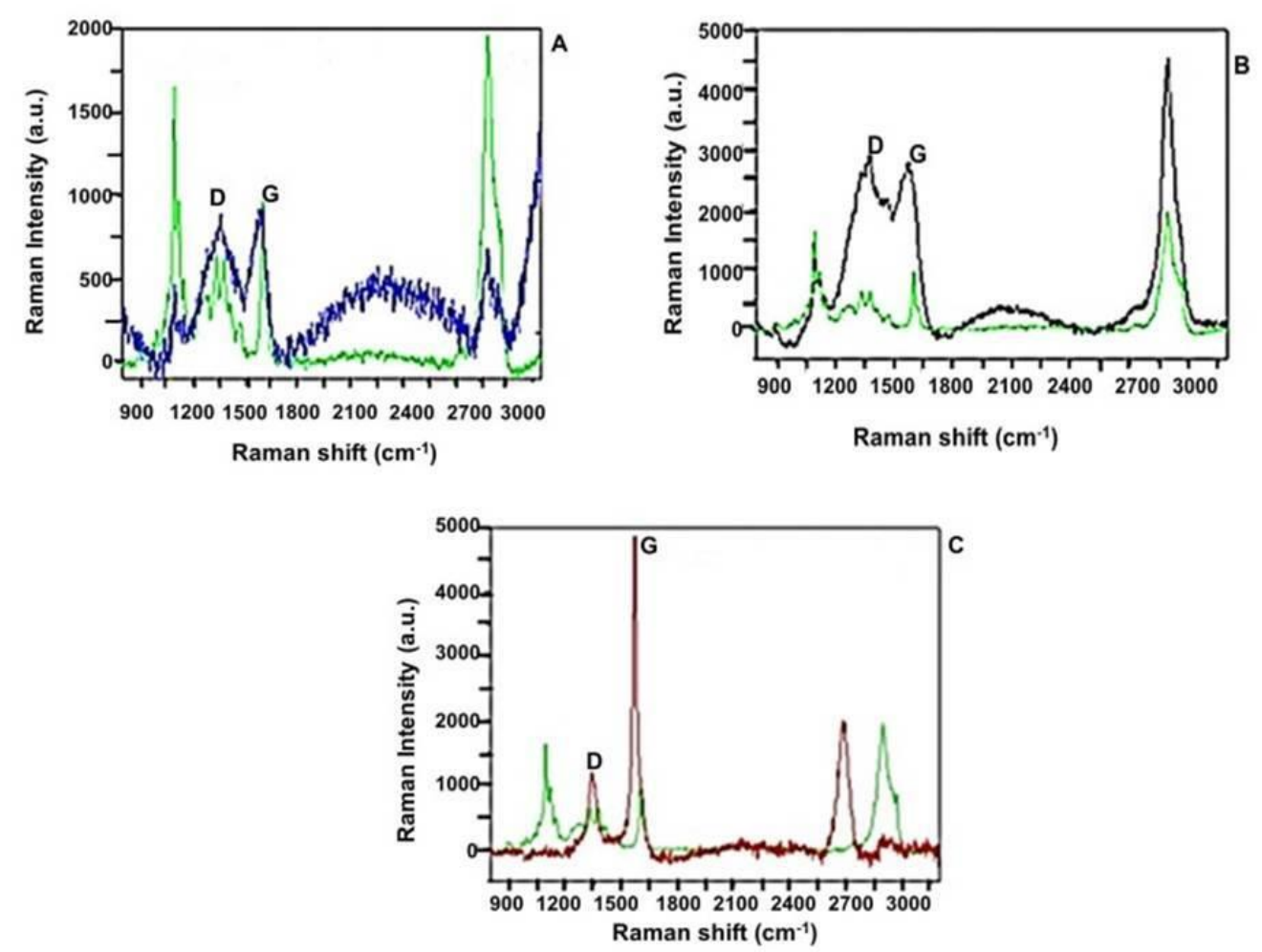

Figure 4. Raman spectroscopy of textiles treated with different concentrations of GO: spectra collected on GO 1\% (A, blue curve), GO 5\% (B, black curve), GO 10\% (C, red curve). Each spectrum is compared with that corresponding to the background signal of the cotton fibers (green curve).

The spectral features corresponding to the textile background can be identified in all reported spectra, together with some specific bands ascribable to the GO structure, such as the two main bands located at about $1570 \mathrm{~cm}^{-1}$ (G peak) and $1350 \mathrm{~cm}^{-1}$ (D peak). The first one shows the graphitic signature of carbon in $\mathrm{GO}$, while the second one is associated with a disorder caused by defects on the $\mathrm{sp}^{2}$ hybridized hexagonal $\mathrm{C}$ sheet. In the case of GO $10 \%$,(Figure 4, panel C), the lower intensity ratio between D and G peaks, is probably due to the larger mean size of the clusters, while a smaller bandwidth for both peaks, and a third GO signature (2D) at about $2683 \mathrm{~cm}^{-1}$, can be attributed to a second-order overtone of the in-plane vibration.

\subsection{Textiles with Different GO Concentrations (5\%, 10\%) Show Different Virus Binding Properties}

Virus adhesion properties of the filters treated with two different $\mathrm{GO}$ concentrations (5\% and $10 \%$ ) were tested and analyzed with SEM. As shown in Figure 5, the lower GO concentration shows few viral particles adhering to the upper surface of filters (panel A) while viral adhesion on upper surfaces of $10 \%$ GO coated fibers was very high (panel B). The lower surfaces of the filters ( $C$ for $5 \%$ and $D$ for $10 \%$ ) show the opposite situation. In filters treated with the highest concentration of GO $(10 \%)$ no aggregates were indeed found adhering to the lower surface of the filter and a high amount of virus was found in the upper surface of the filter. 


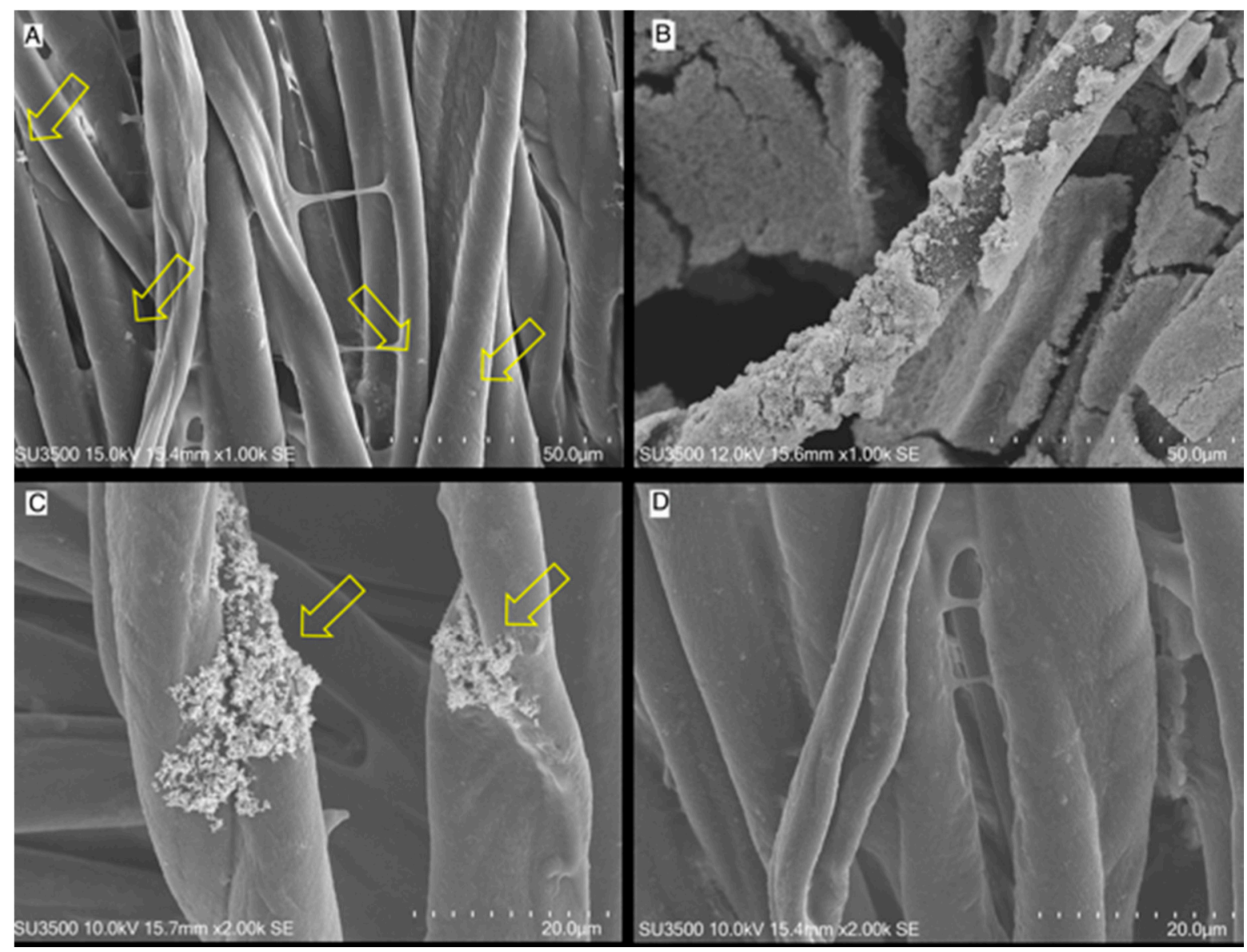

Figure 5. SEM microscopy of GO coated textiles. (A,B) Upper filter surface, (C,D) lower filter surface (A,C) SEM image of $5 \%$ GO coated fibers, arrows point at scattered viral particles aggregates on the upper and lower surfaces of the filters. (B,D) SEM image of 10\% GO coated fibers, arrows point at viral aggregates bound on the upper and lower surfaces of the fibers.

\subsection{Anti-Viral Effect of GO Covered Tissues}

To study if tissues coated with different concentrations of GO (GO-TxT) were able to shield viruses, we evaluated the filtering effect of GO-covered textiles on a model of infection of U373 glioblastoma cells by HHV-6A. This cell line has previously been shown in our laboratory to be efficiently infected by HHV-6A [19]. Textiles coated with different amounts of GO were able to reduce HHV-6A infection of U373 cells in a dose-dependent fashion. This was evaluated by a q-RT-PCR, a quantitative assay showing a slight reduction of viral copy number infecting U373 cells with the tissue without GO (Figure 6 bar 2). The viral copy number decreased by $90 \%$ with GO-T $0.5 \%$, compared to the un-coated control (Figure 6 bar 3), and by $98 \%$ with GO-T 5\% and 95\% with GO-T 10\% (Figure 6, bars 4 and 5, respectively). Therefore, GO was able to prevent the virus from infecting cells placed in the lower wells of plates also at low concentrations. It should be noted that the antiviral capacity of the GO-treated textile was even more efficient than $0.2 \mu \mathrm{m}$ filters (Figure 6, red bar 6) that are routinely used to filter viruses of this size. These results mirror SEM observations shown in Figure 5. No significant toxicity, as determined by the trypan blue exclusion test (data not shown) was found in U373 cells, suggesting that GO/TxT could be safe and used to increase the protection capacity of DPI. The GO-TxT textile was used soon after its production and future studies will clarify the stability of GO bound to this type of textile. 


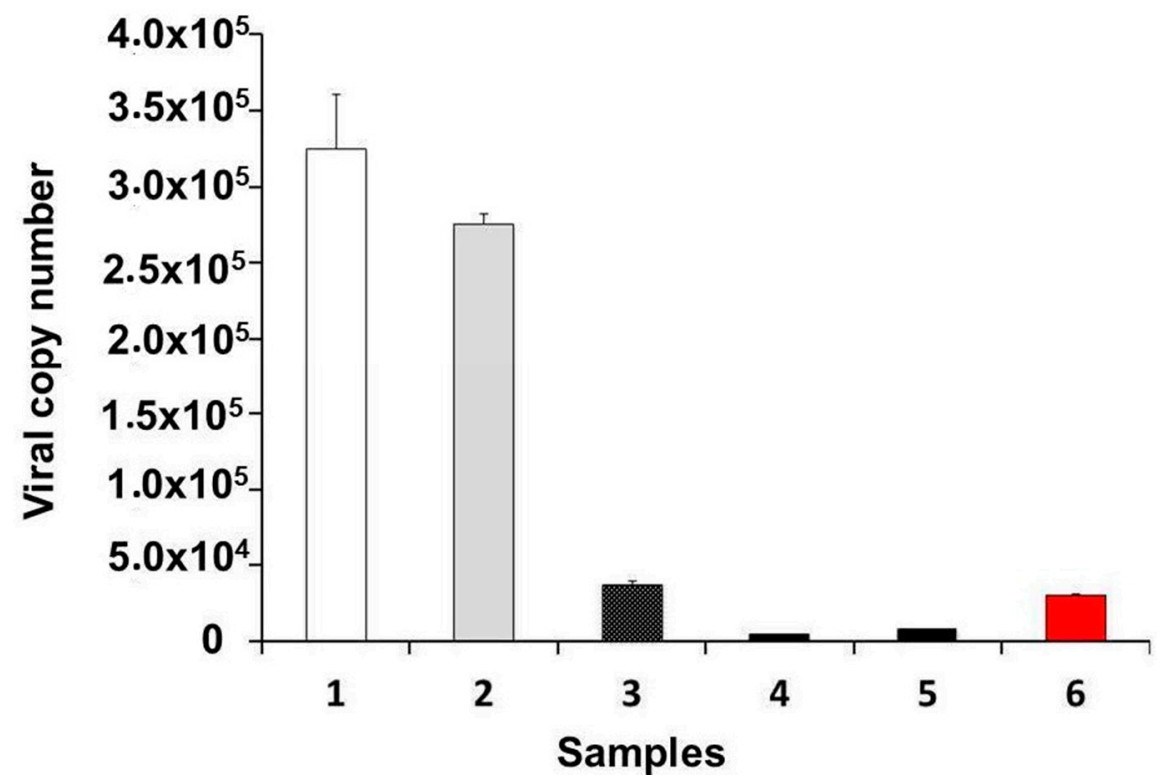

Figure 6. Filtering effect of textiles coated with GO. q-RT PCR on U 373 cells infected with HHV-6A. The virus was allowed to infect cells after passing through different filters. Values are mean of $\mathbf{n} . \mathbf{1}$ : CTRL (NO FILTER NEG.CTRL); 2: CTRL (T); 3: GO-T 0.5; 4: GO-T 5; 5: GO-T 10; 6: $0.2 \mu \mathrm{m}$ filter.

\subsection{Virus Aggregates around GO Sheets}

To highlight the role of GO nanosheets as a virus binding agent, we captured some high magnification images from samples with 10\% GO coated filters incubated with the virus. Figure 7A shows a thick coating of aggregated viral particles. Images at higher magnification (Figure 7B,C) show areas in which GO-coated fibers are surrounded by clusters of aggregated viral particles.

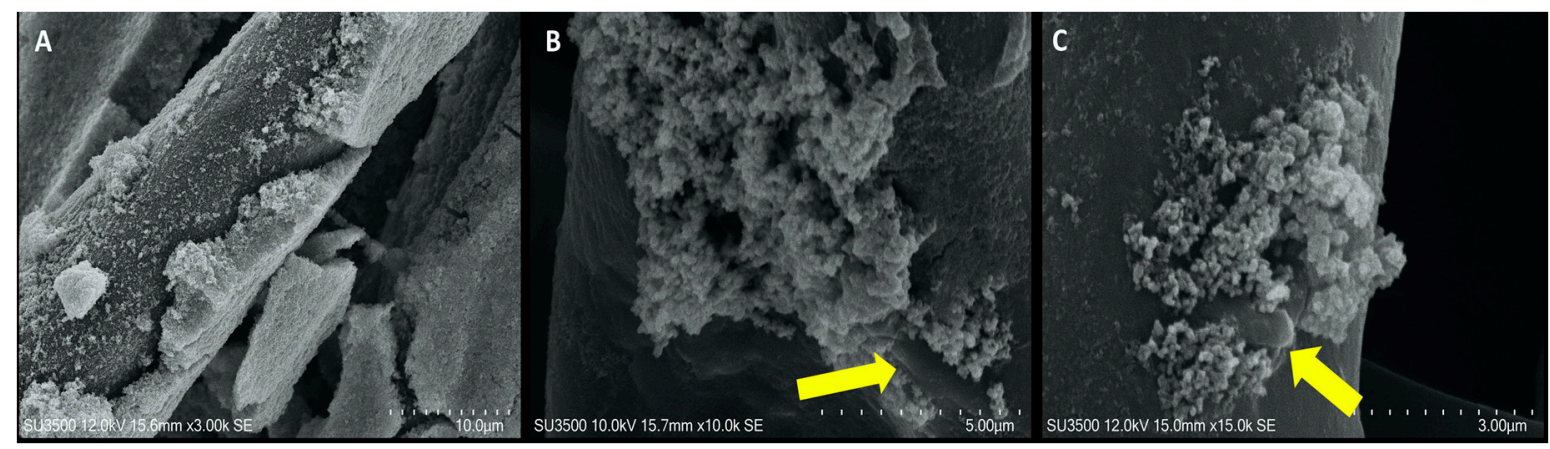

Figure 7. SEM microscopy of textiles used as filters. (A) 10\% GO-coated fibers covered with a thick layer of the virus; (B) GO sheets (arrow) emerging from fiber surface, surrounded by virus particles; (C) GO sheets (arrow) surrounded by viral aggregates.

\section{Discussion}

GO-coated fabrics are attracting great interest from researchers because of the everincreasing demand for protective materials with antiviral capabilities. GO nanoparticles' antiviral properties are attributed to their capacity to bind viruses preventing them to enter and infect target cells [20].

In this study, we demonstrated that GO combined with textiles exhibits antiviral activity towards the HHV-6 virus in a concentration-dependent manner as it prevented its infection of U373 cells. HHV6 virus is an enveloped DNA virus that is ubiquitous in the worldwide population. One of the receptors used mainly by HHV6A to infect cells is CD46 (complement inhibitor receptor), expressed on surfaces of almost every cell type [21]. Apart from specific receptors, infection of cells by herpes viruses depends upon 
the initial attachment of virions to cell surface heparan sulfate, followed by receptor-ligand recognition [22].

GO nanoparticles have been studied for virus detection and disinfection applications [23] given their versatility in binding different molecules and their potential to interfere with viral integrity, especially in the case of enveloped viruses.

Because of the highly reactive ionic groups, GO can bind cotton fabrics [24]. Graphene oxide nanostructures modify multifunctional cotton fabrics [25] in a stable and easy way. The antibacterial efficacy of GO-treated fabrics has been previously demonstrated against both gram-positive and gram-negative bacteria [26].

In this study, GO bound to textiles prevented viral passage through the filter by partially filling the pores of the fabric. However, even when the viral particles passed through low percentage GO-coated filters, they remained attached to the lower surfaces of them, suggesting other mechanisms of interaction.

Apart from its mechanical action on fabric pores, the interaction of GO with viruses has been attributed to factors such as the negative charge of GO as opposed to the positive $\mathrm{Z}$ potential of viral capsids. Our study has shown an increase in $\mathrm{Z}$ potential after binding GO with fabric and a further increase after viral interaction; this may mean that both electrostatic interactions and bio-reduction processes may occur at the same time. On the nanocomposite side, one factor that must be taken into account is the size of GO, which may interfere with viral entry into cells. Ziem et al. [27] have shown that the size of carbon-based nanoarchitectures must adapt to the size of viral particles to inhibit cellular infection. Authors investigating carbon-based viral sensors or direct inhibitors of viral infections have functionalized nanomaterials with substances that lower cytotoxicity and can bind viruses directly [28]. Synthesized GO samples, which consisted of bi-three-layer nanosheets, of $5 \times 10^{-2}-0.2\left(\mu \mathrm{m}^{2}\right)$, seem a useful size for avoiding viral contact with cells.

\section{Conclusions}

In conclusion, we have developed a new method to assess the anti-viral properties of GO and showed that it has filtering capacity when bound to textiles. We suggest that the versatile properties of GO may be used in the future for preventing viral infection as it may be applied to multi-use fabrics with protective masks as well as everyday clothing, linen, or cleaning wipes can be made. Moreover, it has been reported GO can have virucidal properties [29,30], which further encourage its use to protect healthcare personnel from viral infections.

Author Contributions: F.V.: conceptualization, investigation, writing, R.S., M.C. and A.G.: methodology and writing; M.R.: methodology and writing; V.M. and S.D.S.: methodology and writing; A.Z.: writing; S.M.: supervision, writing. All authors have read and agreed to the published version of the manuscript.

Funding: This research received no external funding.

Acknowledgments: Supported by grants Ateneo 2020 Sapienza. The authors would like to thank Hugo Bowles for reading the manuscript and Anna Neri of the department of biomedicine and prevention of Tor Vergata University of Rome for technical support.

Conflicts of Interest: The authors declare no conflict of interests.

\section{References}

1. Weiss, C.; Carriere, M.; Fusco, L.; Capua, I.; Regla-Nava, J.A.; Pasquali, M.; Scott, J.A.; Vitale, F.; Unal, M.A.; Mattevi, C.; et al. Toward nanotechnology-enabled approaches against the COVID-19 pandemic. ACS Nano 2020, 14, 6383-6406. [CrossRef]

2. Valentini, F.; Calcaterra, A.; Ruggiero, V.; Pichichero, E.; Martino, A.; Iosi, F.; Bertuccini, L.; Antonaroli, S.; Mardente, S.; Zicari, A.; et al. Functionalized Graphene Derivatives: Antibacterial Properties and Cytotoxicity. J. Nanomater. 2019. [CrossRef]

3. Sametband, M.; Kalt, I.; Gedanken, A.; Sarid, R. Herpes simplex virus type-1 attachment inhibition by functionalized graphene oxide. ACS Appl. Mater. Interfaces 2014, 6, 1228-1235. [CrossRef]

4. Innocenzi, P.; Stagi, L. Carbon-based antiviral nanomaterials: Graphene, C-dots and fullerenes. A perspective. Chem. Sci. 2020, 11, 6606-6622. [CrossRef] [PubMed] 
5. Natacha, S.O.; Tim, J.D.; Jessika, C.; Ronald, W.A.L.; Yvonne, V.D.M.; Leon, C.; Julian, D.; Jutte, J.C.; Marjolein, K.; Montserrat, B.; et al. SARS-coronavirus-2 replication in Vero E6 cells: Replication kinetics, rapid adaptation and cytopathology. J. Gen. Virol. 2020, 101, 925-940. [CrossRef]

6. Atzori, M.; Artizzu, F.; Sessini, E.; Marchiò, L.; Loche, D.; Serpe, A.; Deplano, P.; Concas, G.; Pop, F.; Avarvari, N.; et al. Halogen-Bonding in a New Family of tris (haloanilato) metallate (III) Magnetic Molecular Building Blocks. Dalton Trans. 2014, 43, 7006-7019. [CrossRef] [PubMed]

7. Baram-Pinto, D.; Shukla, S.; Gedanken, A.; Sarid, R. Inhibition of HSV-1 Attachment, Entry, and Cell-to-Cell Spread by Functionalized Multivalent Gold Nanoparticles. Small 2010, 6, 1044-1050. [CrossRef]

8. Basak, S.; Packirisamy, G. Nano-based antiviral coatings to combat viral infections. Nano-Struct. Nano-Objects 2020, 24, 100620. [CrossRef]

9. Ziem, B.; Rahn, J.; Donskyi, I.; Silberreis, K.; Cuellar, L.; Dernedde, J.; Keil, G.; Mettenleiter, T.C.; Haag, R. Polyvalent 2D Entry Inhibitors for Pseudorabies and African Swine Fever Virus. Macromol. Biosci. 2017, 17, 1600499. [CrossRef]

10. Yang, X.X.; Li, C.M.; Li, Y.F.; Wang, J.; Huang, C.Z. Synergistic antiviral effect of curcumin functionalized graphene oxide against respiratory syncytial virus infection. Nanoscale 2017, 9, 16086-16092. [CrossRef]

11. Donskyi, I.S.; Azab, W.; Cuellar-Camacho, J.L.; Guday, G.; Lippitz, A.; Unger, W.E.S.; Osterrieder, K.; Adeli, M.; Haag, R. Functionalized nanographene sheets with high antiviral activity through synergistic electrostatic and hydrophobic interactions. Nanoscale 2019, 11, 15804-15809. [CrossRef] [PubMed]

12. Li, Y.; Leung, P.; Yao, L.; Song, Q.W.; Newton, E. Antimicrobial effect of surgical masks coated with nanoparticles. J. Hosp. Infect. 2006, 62, 58-63. [CrossRef] [PubMed]

13. Cataldo, F.; Compagnini, G.; Patané, G.; Ursini, O.; Angelini, G.; Ribic, P.R.; Margaritondo, G.; Cricenti, A.; Palleschi, G.; Valentini, F. Graphene nanoribbons produced by the oxidative unzipping of single-wall carbon nanotubes. Carbon 2010, 48, $2596-2602$. [CrossRef]

14. Cullity, B.D. Elements of X-ray Diffraction; Addison-Wesley Pub. Co.: Reading, MA, USA, 1956.

15. Romeo, M.A.; Masuelli, L.; Gaeta, A.; Nazzari, C.; Granato, M.; Gilardini Montani, M.S.; Faggioni, A.; Cirone, M. Impact of HHV-6A and HHV-6B lytic infection on autophagy and endoplasmic reticulum stress. J. Gen. Virol. 2019, 100, 89-98. [CrossRef] [PubMed]

16. Song, J.; Wang, X.; Chang, C.T. Preparation and characterization of graphene oxide. J. Nano Mater. 2014, 2014, 276143. [CrossRef]

17. Marcano, D.C.; Kosynkin, D.V.; Berlin, J.M.; Sinitskii, A.; Sun, Z.; Slesarev, A.; Alemany, L.B.; Lu, W.; Tour, I.M. Improved Synthesis of graphene oxide. ACS Nano 2010, 4, 4806-4814. [CrossRef]

18. De Oliveira Costa, M.A.; Mecheri, B.; D’Epifanio, A.; Placidi, E.; Arciprete, F.; Valentini, F.; Perandini, A.; Valentini, V.; Licoccia, S. Graphene oxide nanoplatforms to enhance catalytic performance of iron phthalocyanine for oxygen reduction reaction in bio electrochemical systems. J. Power Sources 2017, 356, 381-388. [CrossRef]

19. Romeo, M.A.; Gilardini-Montani, M.S.; Gaeta, A.; D’Orazi, G.; Faggioni, A.; Cirone, M. HHV-6A infection dysregulates autophagy/UPR interplay increasing beta amyloid production and tau phosphorylation in astrocytoma cells as well as in primary neurons, possible molecular mechanisms linking viral infection to Alzheimer's disease. BBA 2020, 1866, 165647. [CrossRef]

20. Ye, S.; Shao, K.; Li, Z.; Guo, N.; Zuo, Y.; Li, Q.; Lu, Z.; Chen, L.; He, Q.; Han, H. Antiviral Activity of Graphene Oxide: How Sharp Edged Structure and Charge Matter. ACS Appl. Mater. Interfaces 2015, 7, 21571-21579. [CrossRef]

21. Dunn, N.; Kharlamova, N.; Fogdell-Hahn, A. The role of herpesvirus 6A and 6B in multiple sclerosis and epilepsy. Scand. J. Immunol. 2020, 92, e12984. [CrossRef]

22. Choudhary, S.; Marquez, M.; Alencastro, F.; Spors, F.; Zhao, Y.; Tiwari, V. Herpes Simplex Virus Type-1 (HSV-1) Entry into Human Mesenchymal Stem Cells Is Heavily Dependent on Heparan Sulfate. J. Biomed. Biotechnol. 2011, 2011, 264350. [CrossRef] [PubMed]

23. Song, Z.; Wang, X.; Zhu, G.; Nian, Q.; Zhou, H.; Yang, D.; Qin, C.; Tang, R. Virus capture and destruction by label-free graphene oxide for detection and disinfection applications. Small 2015, 11, 1171-1176. [CrossRef]

24. Karthikeyan, K.; Navaneethaiyer, U.; Mohan, R.; Jehee, L.; Sang-Jae, K. Graphene oxide nanostructures modified multifunctional cotton fabrics. Appl. Nanosci. 2012, 2, 119-126. [CrossRef]

25. Vaideki, K.; Jayakumar, S.; Thilagavathi, G.; Rajendran, R. A study on the antimicrobial efficacy of RF oxygen plasma and neem extract treated cotton fabrics. Appl. Surf. Sci. 2007, 253, 7323-7329. [CrossRef]

26. Li, D.; Zhang, W.; Xiaoqing, Y.; Wang, Z.; Su, Z.; Wei, G. When biomolecules meet graphene: From molecular level interactions to material design and applications. Nanoscale 2016, 8, 19491-19509. [CrossRef] [PubMed]

27. Ziem, B.; Azab, W.; Gholami, M.F.; Rabe, J.; Osterrieder, P.; Haag, R. Size-dependent Inhibition of Herpesvirus Cellular Entry by Polyvalent Nanoarchitectures. Nanoscale 2017, 9, 3774-3783. [CrossRef]

28. Srivastava, A.K.; Dwivedi, N.; Dhand, C.; Khan, R.; Sathish, N.; Gupta, M.K.; Kumar, R.; Kumar, S. Potential of graphene-based materials to combat COVID-19: Properties, perspectives, and prospects. Mater. Today Chem. 2020, 18, 100385. [CrossRef] [PubMed] 
29. Donskyi, I.; Drüke, M.; Silberreis, K.; Lauster, D.; Ludwig, K.; Kühne, C.; Unger, W.; Böttcher, C.; Herrmann, A.; Dernedde, J.; et al. Interactions of Fullerene-Polyglycerol Sulfates at Viral and Cellular Interfaces. Small 2018, 14, 1800189. [CrossRef]

30. Matharu, R.K.; Porwal, H.; Chen, B.; Ciric, L.; Edirisinghe, M. Viral Filtration Using Carbon-Based Materials. Med. Devices Sens. 2020, 3, e10107. [CrossRef] 